\title{
ESTUDO PILOTO: A REALIZAÇÃO VARIÁVEL DO DITONGO /ow/ EM AMOSTRA DE FALA DA PRAÇA 14 DE JANEIRO EM MANAUS (AM)
}

\section{PILOT STUDY: THE VARIABLE REALIZATION OF THE DIPHTHONG /OW/ IN SPEECH SAMPLE OF THE PRAÇA 14 DE JANEIRO IN MANAUS (AM)}

\author{
Geise Freitas de Oliveira* \\ UFAM
}

\section{Flávia Santos Martins** UFAM}

\begin{abstract}
Resumo: Este artigo é de cunho sociolinguístico (LABOV, 2008 [1972]) e tem como objetivo investigar a realização variável do ditongo /ow/ em amostra de fala da Praça 14 de Janeiro, em Manaus (AM). O corpus foi retirado de um banco de dados formado de seis entrevistas sociolinguísticas com informantes divididos em três faixas etárias: 18 a 35 anos, 36 a 55 e 56 em diante, sendo um homem e uma mulher para cada faixa, todos com 4 a 8 anos de escolarização. Para a análise dos dados, utilizou-se o programa estatístico GoldVarb X (SANKOFF; TAGLIAMONTE; SMITH, 2005), em que foram controladas as variáveis linguísticas "posição do ditongo na palavra", "tonicidade", "classe gramatical” e "contexto seguinte”; e as variáveis sociais “sexo”e "faixa etária”. Os resultados mostraram que a monotongação do ditongo /ow/ ainda não se efetivou em nossa amostra de fala, uma vez que ocorreu em 65,1\% dos dados, estando em variação com a sua manutenção (34,9\%). Das variáveis controladas, que mostraram atuar na redução do ditongo, o programa selecionou, conforme ordem de relevância, "faixa etária”, "contexto seguinte", "sexo" e "tonicidade".
\end{abstract}

Palavras-Chave: Sociolinguística. Variação. Ditongo. Monotongação.

\begin{abstract}
This article is of a sociolinguistic nature (LABOV, 2008 [1972]) and proposes to investigate the variable realization of the diphthong /ow/ in a speech sample of the Praça 14 de Janeiro, in Manaus (AM). The corpus was taken from a database made up of six sociolinguistic interviews with informants divided into three age groups: 18 to 35 years old, 36 to 55 and 56 onwards, one man and one woman for each age group, all with 4 to 8 years of schooling. For data analysis, the statistical software GoldVarb X (SANKOFF; TAGLIAMONTE; SMITH, 2005) was used, and the linguistic variables diphthong position in the word, stress, word class and following context, and the social variables sex and age group were controlled. The results demonstrated that the monophthongization of the diphthong /ow/ has not yet consolidated in our speech sample, since it occurred in $65.1 \%$ of the data, being in variation with its
\end{abstract}

\footnotetext{
* Mestranda do Programa de Pós-Graduação em Letras - Linha de Pesquisa Sociolinguística/Dialetologia - da Universidade Federal do Amazonas (PPGL/UFAM). E-mail: ghidaka@gmail.com.

** Doutora em Linguística pela Universidade Federal de Santa Catarina (UFSC). Professora da Universidade Federal do Amazonas (UFAM). E-mail: flavinhaingrid@yahoo.com.br.
} 
maintenance (34.9\%). Of the controlled variables that are shown to act in the reduction of diphthong, the software selected, in order of relevance, age group, next context, sex and stress.

Keywords: Sociolinguistics. Variation. Diphthong. Monophthongization.

\section{INTRODUÇÃO}

Entender os fenômenos em variação de uma língua é também entender como uma língua funciona. A variação linguística, “[...] o processo pelo qual duas formas [ou mais] podem ocorrer no mesmo contexto com o mesmo valor referencial/representacional" (COELHO et al., 2018, p. 16), ou seja, com o mesmo valor de verdade, é inerente à língua e está presente em todos os níveis gramaticais. Um indivíduo pode falar de maneiras diferentes a depender do local em que vive, da idade, do grau de escolaridade, do status social, da situação de comunicação e muitos outros grupos de fatores que podem condicionar sua "escolha” na hora de falar, sejam eles linguísticos ou extralinguísticos. Por isso, é importante estudar a variação em todos os níveis linguísticos, e um dos níveis que oferece uma série de fenômenos para o estudo da variação é o nível fonético-fonológico. Posto isso, este artigo faz um estudo piloto, por meio de uma pesquisa de campo, da realização variável do ditongo /ow/, que pode se realizar como [ow] mantendo a vogal e o glide em sua produção, como em "roupa" e "chegou”, por exemplo, ou passar pelo processo de monotongação e ser reduzido a um único segmento vocálico e ser realizado como [o], como em "ropa” e "chegô".

Desse modo, este estudo piloto tem como objetivo geral investigar a realização variável do ditongo /ow/ em amostra de fala dos moradores da Praça 14 de Janeiro em Manaus (AM). Para isso, foram traçados os seguintes objetivos específicos: descrever como o ditongo /ow/ é realizado, com a sua manutenção como [ow] ou reduzido para [o], na fala dos moradores da Praça 14 de Janeiro em Manaus (AM); e analisar os condicionadores linguísticos e extralinguísticos que podem influenciar a realização variável de /ow/ na fala desses moradores.

Neste trabalho, adotamos os pressupostos teórico-metodológicos propostos por Labov (2008 [1972]) quanto aos aspectos gerais da Sociolinguística, além de Coelho et al. (2018) e Guy e Zilles (2007). Sobre os ditongos no Português do Brasil (PB), consultamos Bisol (1999), Cagliari (2007), Seara, Nunes e Lazzarotto-Volcão (2019) e Silva (2014, 2015). Acerca de nosso fenômeno variável, apoiamo-nos nas pesquisas de Carvalho (2007), Cristofolini (2011), Cruz (2004), Lopes (2002), Maria Silva (2017) e Veado (1983).

Iniciamos nosso estudo trazendo algumas questões teóricas sobre os ditongos orais decrescentes e sua redução no PB. Em seguida, apresentamos brevemente alguns estudos sobre a variação na realização de /ow/ em diferentes regiões do Brasil e seus principais resultados. No próximo tópico, discorremos sobre as questões metodológicas que envolveram a construção deste estudo. Os resultados desta pesquisa são apresentados e discutidos na seção seguinte de acordo com as variáveis selecionadas como relevantes pelo programa estatístico GoldVarb X. Por fim, apresentamos algumas considerações sobre os principais resultados desta pesquisa. 


\section{OS DITONGOS ORAIS DECRESCENTES E SUA REDUÇÃO NO PORTUGUÊS DO BRASIL}

Antes de tratarmos de nosso objeto de estudo, é necessário fazermos algumas considerações sobre os ditongos, mesmo se a noção de ditongo nos seja familiar.

Cagliari (2007, p. 69) afirma que o ditongo tem uma articulação específica e própria e “[...] se realiza por um movimento contínuo da língua, indo de uma posição articulatória própria de uma vogal à posição articulatória própria de uma outra vogal, produzindo auditivamente um som vocálico de qualidade em constante mudança”. Ademais, o ditongo ocorre em uma única sílaba, diferente da sequência de duas vogais, em que há uma fronteira silábica. Silva (2014, p. 94) reitera que "[...] um ditongo consiste de uma sequência de segmentos vocálicos sendo que um dos segmentos é interpretado como vogal e o outro é interpretado como um glide". Segundo a autora, glides podem apresentar características fonéticas de segmentos vocálicos ou consonantais, por isso são também chamados de semivocoides, semicontoides, semivogais ou vogais assilábicas. É a função do glide na estrutura sonora de uma língua que justificará se tal segmento será interpretado como vogal ou consoante. Já Seara, Nunes e Lazzarotto-Volcão (2019) definem os ditongos como dois segmentos vocálicos em sequência em uma mesma sílaba, podendo se apresentar como vogal-semivogal ou semivogal-vogal. Os ditongos finalizados em semivogal são chamados de decrescentes, pois terminam pelo segmento de menor proeminência acentual como em "gaita"; e os finalizados em vogal, segmento com maior proeminência acentual como em "farmácia", são chamados de crescentes. Os ditongos podem ainda ser orais ou nasais.

Alguns ditongos podem ser reduzidos a um segmento, resultado de um fenômeno fonológico chamado de monotongação, em que um ditongo passa a ser realizado como um monotongo, ou seja, como uma única vogal (SILVA, 2014, 2015). Nesse caso, o glide não se manifesta foneticamente e palavras como "caixa”, "feira" e "cenoura" passam a ser realizadas como "caxa”, "fera” e "cenora”, respectivamente. Silva (2014) afirma que a redução pode ocorrer em diferentes classes gramaticais como substantivos, adjetivos e formas verbais. No entanto, há casos em que a redução não se aplica, como em "sai", "sei” e "Moscou".

Para Bisol (1999), a redução de /ow/ a um monotongo ocorre por apagamento ou reanálise. Segundo a autora, "interpretá-lo como reanálise significa que os falantes não têm mais o ditongo /ow/, mas sim, a vogal simples /o/ na forma subjacente” (BISOL, 1999, p. 116) e enfatiza que isso não ocorre com o ditongo [ow] derivado de /ol/, como em "folclore", porque este não é ditongo subjacente.

Outra interpretação é que a monotongação ocorre por assimilação da altura, uma vez que os segmentos vocálicos dos ditongos decrescentes que podem ser reduzidos, nesse caso /ow/, são foneticamente semelhantes, sendo posteriores, arredondados e distinguem-se apenas pela altura, que, aliás, é bem próxima. Dessa forma, a vogal, segmento com proeminência acentual, compartilha a propriedade de altura com a semivogal, segmento de menor proeminência e menor duração, ocasionando seu apagamento.

Partimos agora para uma perspectiva variacionista da realização variável de /ow/ a fim de investigar que condicionadores, sejam eles estruturais ou não, podem influenciar para a ocorrência da monotongação em nossa amostra. 


\section{A REALIZAÇÃO VARIÁVEL DE /OW/ NO BRASIL: ESTUDOS EMPÍRICOS}

Vários estudos sobre a realização variável de /ow/ foram feitos no Brasil. Vejamos, de forma sucinta, os principais resultados de algumas pesquisas sobre esse fenômeno.

O estudo-piloto de Veado (1983) analisou as alternâncias de [ow] [o] e [ej] [e] na região metropolitana de Belo Horizonte por meio da fala casual, fala cuidada e leitura de texto. Os informantes foram estratificados de acordo com "classe social” (média e alta), "faixa etária” (jovens, velhos e adultos) e "sexo” (masculino e feminino). Sobre o ditongo /ow/, a autora não encontrou contextos estruturais bloqueadores e concluiu que a fala casual favorece a redução, o que ocorreu em $99 \%$ de seus dados, independente de grupos de fatores como "posição que o ditongo ocupa no léxico”, "traço [ \pm acento]”, "segmentos consonantais adjacentes” ou qualquer "traço morfológico”. Grupos de fatores não estruturais como “classe social”, “idade” e "sexo” também não apresentaram influência no favorecimento ou desfavorecimento da redução. Na fala cuidada, retirada de noticiários, a autora afirma que a redução não ocorre da mesma maneira. Quanto à “posição”, o ambiente com maior frequência de redução foi final de palavra com 78,7\% das ocorrências, embora a autora afirme que não se pode dizer que as outras posições são desfavorecedoras. Quanto à “tonicidade”, o traço [+acento] obteve a maior frequência de redução, com 67,8\% das ocorrências. Sobre o "segmento consonantal seguinte”, excluindo o ambiente final de palavra, restaram apenas 56 dados, dos quais 44 foram ocupados pelos itens lexicais “outro”, “pouco” e “ouvi”, não sendo possível afirmar se o contexto seguinte tem influência ou não na redução do ditongo /ow/. Nos testes de leitura, a autora afirma que os resultados na leitura de sentenças foram semelhantes aos registrados nas entrevistas e nos noticiários, porém na leitura de palavras, o percentual de redução baixou significativamente, atingindo apenas 23,8\% de redução. Os dados demonstraram que somente em registro muito formal de fala é que os ditongos são mantidos, embora nunca categoricamente. Apesar de empregar os termos "favorecimento" e “desfavorecimento", a autora não utilizou programa estatístico para a análise dos dados, apresentando seus resultados apenas em percentuais de ocorrência.

Lopes (2002) investigou a regra de redução dos ditongos /ow/ e /ej/ em Altamira (PA) com dados do projeto Atlas Geo-Sociolinguístico do Estado do Pará (ALIPA), no qual analisou entrevistas de 40 informantes estratificados de acordo com "sexo" (masculino e feminino), "escolaridade” (não escolarizado, ensino fundamental, ensino médio), "idade” (15 a 25 anos, 26 a 45 anos e 46 a 70 anos) e "renda” (baixa e média). Para as 1456 ocorrências do ditongo /ow/, a forma reduzida [o] foi utilizada em 95\% dos dados. Os grupos de fatores controlados na pesquisa foram: "classe morfológica”, "posição do ditongo no vocábulo”, "tonicidade”, "localização do ditongo na estrutura morfológica da palavra”, "contexto fonético seguinte”, "contexto fonético precedente”, "natureza de origem/uso do vocábulo” e "status fonológico do ditongo” (linguísticos); “sexo”, “idade”, “escolaridade” e "renda” (sociais). Das oito variáveis linguísticas, o programa estatístico selecionou apenas três como relevantes para a redução de /ow/: a "posição do ditongo na palavra”, em que o fator favorecedor foi a "posição final” com 99\% de frequência e peso relativo (PR) de 0,77; o "contexto fonético seguinte”, cujos fatores "velar [k]” (93\%, PR 0,87) e "bilabial [p, b]” (98\%, PR 0,86) foram os mais favorecedores para aplicação da regra; e o "contexto fonético precedente”, em que a monotongação de /ow/ se mostrou favorecida quando precedido de "tepe” (97\%, PR 0,83) e “pausa” (96\%, PR 0,70). Das variáveis sociais, apenas a "escolaridade” foi selecionada e o fator “não-escolaridade” foi o 
favorecedor para a aplicação da regra com 99\% de frequência e peso relativo 0,82. Para a autora, a monotongação de /ow/ praticamente não encontra ambientes bloqueadores, apresentando-se como um fenômeno bastante difundido em Altamira (PA).

Carvalho (2007) realizou um estudo sobre o apagamento dos glides que compõem os ditongos decrescentes orais /aj/, /ej/, /oj/, /aw/, /ew/, /ow/ na fala de Recife em amostra constituída por 48 informantes (24 residentes em bairros de periferia e 24 em bairros centrais) estratificados de acordo com "faixa etária”, "sexo”, "escolaridade” e "localização de moradia”, uma vez que informantes dos bairros centrais apresentavam um poder aquisitivo bem maior do que os residentes das periferias. Seus dados foram divididos de acordo com as ocorrências de /j/e /w/. A autora utilizou duas formas de coleta de dados: entrevista e leitura, sendo a leitura dividida em lista de palavras e texto. Seus resultados não mostraram diferença entre a fala espontânea e a fala monitorada pela leitura. Para os grupos de fatores sociais, a autora controlou: "sexo", "faixa etária”, "escolaridade” e "localização de moradia”. Já para os linguísticos, a autora considerou: "posição do ditongo", "tonicidade”, "contexto precedente”, "contexto seguinte” e "classe gramatical". O ditongo /ow/ foi o que sofreu mais apagamento do glide e as variáveis selecionadas pelo programa, por ordem de significância, como favorecedoras para a redução, foram: "escolaridade", "idade” e "localização de moradia” (sociais); "tonicidade”, "contexto fonológico precedente" e "contexto fonológico seguinte" (estruturais). Nessa pesquisa, falantes com menos escolaridade (até 4 anos) mostraram-se favorecedores do apagamento do glide, com peso relativo 0,58 , enquanto os que apresentavam mais de quatro anos o desfavoreceram $(0,40)$. No grupo "faixa etária”, o fator favorecedor foi a segunda faixa (26 a 49 anos) com 0,63 e o desfavorecedor foi a última faixa (50 anos em diante) com 0,38. Sobre a "localização de moradia”, falantes de bairros de subúrbio aplicaram mais a regra de redução $(0,57)$ do que falantes de bairros centrais $(0,37)$. Acerca dos condicionadores linguísticos, a "tonicidade" foi a primeira variável selecionada como favorecedora para a redução, em que ditongos localizados em sílabas tônicas apresentaram o peso relativo 0,59 contra 0,39 das pretônicas, possivelmente pelo grande índice de ocorrência do ditongo /ow/ nas desinências verbais de terceira pessoa. Para o "contexto fonológico precedente", o fator que se mostrou mais favorecedor foi a "vogal posterior /o/" (0,64), ou seja, o ditongo /ow/ apresentou maior grau de redução. Para o "contexto fonológico seguinte", o fator "fricativa labial" apresentou-se como maior favorecedor do apagamento do glide /w/ $(0,80)$, seguido de "tepe" $(0,57)$.

Cristofolini (2011) estudou a monotongação de [ow] na comunidade de Ratones em Florianópolis sob a perspectiva acústica e sociolinguística. Foram selecionados oito informantes, divididos por "escolaridade" (ensino fundamental e superior) e "faixa etária" (menos de 35 anos e mais de 50 anos de idade). Seus resultados mostraram uma redução do ditongo quase categórica, com 93\% dos dados monotongados. Acerca da perspectiva sociolinguística, a pesquisadora controlou as seguintes variáveis independentes linguísticas: "classe de palavra”, "contexto fonológico posterior”, "posição na palavra” e "tonicidade da sílaba”. As variáveis extralinguísticas controladas foram: "idade" e "escolaridade”. Das variáveis controladas, apenas a "tonicidade da sílaba" foi selecionada como relevante, sendo o fator "tônico" o favorecedor para a redução do ditongo com $98 \%$ de frequência e peso relativo de 0,63 e o fator "átono" o desfavorecedor com $57 \%$ de frequência e 0,04 de peso relativo. 
Acerca dos estudos no Amazonas, especificamente, podemos destacar o de Cruz (2004) e o de Maria Silva (2017). Em seu estudo dialetológico para a construção do Atlas Linguístico do Amazonas (ALAM), Cruz (2004) investigou a realização do ditongo /ow/ em nove pontos de inquérito, cada um representando uma das nove Microrregiões do Estado do Amazonas, sendo eles: Barcelos, Tefé, Benjamin Constant, Eirunepé, Lábrea, Humaitá, Manacapuru, Itacoatiara e Parintins. Em cada ponto, foram selecionados seis informantes divididos em três "faixas etárias" (faixa 1 - 18 a 35 anos, faixa 2 - 36 a 55 anos e faixa 3 - 56 em diante), sendo um homem e uma mulher para cada faixa, analfabetos ou até a $4^{\text {a }}$ série. Para analisar a realização variável de /ow/, foram selecionados cinco itens lexicais que geraram cinco cartas linguísticas. Seus resultados gerais apontaram que, embora a redução para [o] seja considerada como praticamente efetivada no PB, a manutenção do ditongo ainda é bastante produtiva nos falares amazonenses, ocorrendo em 49,3\% dos dados, contra 50,6\% de monotongação. Devemos destacar que a pesquisadora não utilizou programa estatístico e não fez controle de variáveis independentes linguísticas. No que se refere ao índice de monotongação por “sexo" e "idade”, a autora não faz considerações de acordo com a estratificação social dos informantes, mas o que pode ser observado a partir dos gráficos e das cartas fonéticas é que, em torno de 56\% dos dados monotongados, foram produzidos por homens; em relação à “idade”, falantes da faixa 3, acima de 56 anos, produziram aproximadamente $42 \%$ do total de dados monotongados.

Maria Silva (2017) estudou a monotongação sob o viés da interferência da fala na escrita em 292 textos de alunos das $1^{\mathrm{a}}$, $2^{\mathrm{a}}$ e $3^{\mathrm{a}}$ séries do ensino médio integrado ao técnico do Instituto Federal do Amazonas (IFAM) - Campus Manaus Zona Leste, sendo 146 participantes do "sexo feminino” e 146 do “sexo masculino”. Os dados do corpus foram submetidos à análise por meio do programa Excel, por isso os resultados são apresentados em forma de percentual. Na análise da variação [ow] [o], a autora observou o “contexto fonológico seguinte”, considerando os fatores: oclusiva labial [p, b, v], tepe, coronal menos tepe [t, s], dorsal [k] e final absoluto. O "nível escolar” e o "sexo" também foram controlados. Os resultados mostraram que, mesmo na escrita, ocorre a redução do ditongo, uma vez que, de 999 ocorrências para o ditongo /ow/, em 8,91\% houve redução para [o]. O contexto final absoluto foi o que mais apresentou apagamento, com 11,92\% de frequência, o que corresponde a 88 ocorrências. Nos demais contextos, praticamente não houve apagamento de [w]. Na variável “nível escolar”, os resultados mostraram que, à medida que os alunos avançavam nas séries, a redução do ditongo diminuía na escrita. Quanto ao “sexo”, os resultados não mostraram diferenças expressivas no índice de apagamento de $[w]$ entre homens e mulheres. Os resultados sugerem que, na escrita, a redução do ditongo é pouco produtiva e diminui à medida que os alunos progridem nas séries.

Podemos observar que a maioria dessas pesquisas apresenta a redução do ditongo /ow/ como praticamente efetivada na fala do PB, pois a forma monotongada atinge mais de $90 \%$ das ocorrências. A única pesquisa com dados de fala que obteve um índice menor de monotongação de /ow/, com 50,6\% de ocorrências, foi a de Cruz (2004), um estudo que utilizou a metodologia da Dialetologia com aplicação de Questionário Fonético-Fonológico para a coleta de dados, um registro um pouco mais formal do que a entrevista sociolinguística, com um número pequeno de itens lexicais com o ditongo em estudo por informante e sem o controle de variáveis linguísticas.

Esses trabalhos, portanto, mostram que, embora a redução de /ow/ esteja bastante difundida no Brasil, ainda se faz necessário um estudo mais aprofundado no Amazonas. 


\section{PROCEDIMENTOS METODOLÓGICOS}

Esta é uma pesquisa sociolinguística feita a partir de dados linguísticos efetivamente produzidos. Por ser uma pesquisa variacionista, utilizamos a metodologia da pesquisa Sociolinguística Laboviana (LABOV, 2008 [1972]), também chamada de Quantitativa, uma vez que se baseia na frequência de uso das variantes linguísticas e utiliza métodos estatísticos para comparação, análise e apresentação dos dados (GUY; ZILLES, 2007).

\section{A AMOSTRA E A COLETA DE DADOS: ESTUDO PILOTO}

Nossa amostra é constituída de seis entrevistas gravadas em novembro de 2019 pelos discentes da disciplina Tópicos Especiais em Linguística 18 - Sociolinguística, do Programa de Pós-Graduação em Letras da Universidade Federal do Amazonas. Para que os dados de nossa amostra representassem com maior fidelidade a "comunidade de fala" estudada, o bairro Praça 14 de Janeiro em Manaus (AM), o informante deveria obedecer a alguns critérios: estar cursando ou ter cursado até o ensino fundamental completo, ter nascido e vivido no bairro, assim como seus pais, e que não tivesse se afastado por mais de 10 anos do seu local de nascimento. Assim, foram selecionados os seis informantes, com a seguinte estratificação social:

Tabela 1: Estratificação social dos informantes

\begin{tabular}{c|c|c|c|c|c|c}
\hline Faixa etária & \multicolumn{2}{|c|}{$\mathbf{1 8}$ a $\mathbf{3 5}$ anos } & \multicolumn{2}{c|}{36 a $\mathbf{5 5}$ anos } & \multicolumn{2}{c}{$\mathbf{5 6}$ em diante } \\
\hline Sexo & Homem & Mulher & Homem & Mulher & Homem & Mulher \\
\hline $\begin{array}{l}\text { 4 a } 8 \text { anos de } \\
\text { escolarização }\end{array}$ & 1 & 1 & 1 & 1 & 1 & 1 \\
\hline
\end{tabular}

Fonte: Elaboração própria

O instrumento utilizado para a coleta de dados foi a entrevista sociolinguística, conduzida por meio de um roteiro semiestruturado com foco para as narrativas de experiências pessoais, sobretudo no que se referia à vivência do informante no bairro. Para o registro dos dados, foi utilizado um gravador de voz portátil e Smartphones.

\section{A CONSTITUIÇÃO DO CORPUS: ALGUMAS CONSIDERAÇÕES}

Depois de constituirmos nosso banco de dados, conforme descrito na subseção anterior, iniciamos o exame das entrevistas para retirar o corpus para a análise. Os dados foram transcritos foneticamente de acordo com as ocorrências de itens lexicais com uma das variantes de /ow/, sua manutenção como [ow] ou sua monotongação para [o]. Além da realização variável de /ow/ correspondente ao "ou" ortográfico, também transcrevemos os casos oriundos da vocalização de "ol”, como em "resolvo", realizado como "res[ow]vo", totalizando 30 dados. Visto que não houve variação nas ocorrências provenientes da vocalização de "ol”, realizado sempre como [ow], tais dados não foram incluídos no corpus, uma vez que o ditongo se manteve de forma categórica. 
Com isso, obtivemos 350 dados com a ocorrência de uma das variantes de /ow/. Porém, segundo Guy e Zilles (2007), em uma análise quantitativa é preciso ter cuidado na hora de incluir ou não no corpus um possível dado, sobretudo os casos em que há dúvidas sobre como classificar a ocorrência em termos de valor da variável dependente. Dessa forma, fizemos uma reanálise dos dados para a eliminação dos casos duvidosos, que, se inseridos no corpus, poderiam gerar resultados enviesados ou falsos. Por isso, ocorrências de /ow/ em contextos neutralizantes, ou seja, em que não era possível distinguir uma das variantes de nossa variável dependente, como em “comprou um”, foram excluídas.

Depois da retirada dos casos duvidosos, restaram 318 dados que formaram nosso corpus, os quais foram categorizados e submetidos a análises estatísticas realizadas pelo programa GoldVarb X (SANKOFF; TAGLIAMONTE; SMITH, 2005) que selecionou os grupos de fatores favorecedores para a redução do ditongo, o número de ocorrências e a frequência de uso, conforme descritas adiante.

\section{O BAIRRO PRAÇA 14 DE JANEIRO: UM RECORTE DO PERFIL SÓCIO- HISTÓRICO}

Segundo Pedrosa (2020), o bairro Praça 14 de Janeiro, localizado na zona Sul de Manaus, é um dos mais antigos da cidade. Ao longo de sua história, o bairro teve diferentes nomes: Vila Maranhense, Praça da Conciliação, Praça Fernandes Pimenta, Praça 14 e Praça Portugal. A partir da década de 1950, passou a se chamar definitivamente Praça 14 de Janeiro, em alusão a uma revolta motivada por disputas políticas e liderada por funcionários públicos no dia de 14 de Janeiro de 1892, que acabou culminando na derrubada do Governador Gregório Thaumaturgo de Azevedo e na ascensão de Eduardo Gonçalves Ribeiro ao poder.

Conforme informações publicadas pelo Jornal Em Tempo e Jornal do Commercio, a famosa data marcou oficialmente a fundação do bairro, embora a área tenha começado a ser ocupada bem antes, no início dos anos 1880, em sua maioria por ex-escravos maranhenses que vieram para atuar nas grandes obras de melhoramento urbano que estavam sendo executadas na cidade. Esses operários passaram a residir na região, marcando sua identidade por meio de manifestações artísticas e religiosas afro-brasileiras. A comunidade negra que ainda reside no referido bairro foi transformada em quilombo, o “Quilombo do Barranco”, a segunda comunidade quilombola em área urbana do Brasil, título concedido em 2014 pela Fundação Palmares (PRAÇA 14, 2005; PRAÇA 14, 2019).

De acordo com Pedrosa (2020), nos primeiros anos de surgimento do bairro, além dos negros oriundos do Maranhão, a área também era ocupada por imigrantes portugueses que mantiveram suas tradições que moldaram o local, como os festejos de São Benedito e de Nossa Senhora de Fátima. As manifestações religiosas católicas têm grande expressividade no bairro, com duas igrejas monumentais, o Santuário de Nossa Senhora de Fátima, a padroeira do bairro, construído entre 1942 e 1975, e a Paróquia de São José Operário, construída entre 1949 e 1967, famosa por suas novenas mensais que atraem milhares de fiéis.

Conforme Nunes (2018), além das manifestações religiosas, o bairro é também conhecido pelas manifestações carnavalescas. Considerado o "berço do samba” de Manaus, foi na Praça 14 que surgiu a primeira escola de samba da cidade, fundada em 1946, chamada de Escola 
Mixta de Samba da Praça 14 de Janeiro, que existiu até o ano de 1962 e que se tornaria o embrião para a fundação, em dezembro de 1975, da Escola de Samba Vitória Régia, uma das mais tradicionais do carnaval manauara, representado pelas cores verde e rosa, e que esteve presente em todos os desfiles desde a sua criação, acumulando 11 títulos de campeã do Carnaval de Manaus.

Segundo o Jornal Em Tempo, as primeiras melhorias na paisagem urbana da Praça 14 como asfaltamento de ruas, luz elétrica, postos médicos, maternidade, postos policiais, escolas e feiras surgiram entre as décadas de 1950 e 1960, nos Governos de Plínio Ramos Coelho e de Gilberto Mestrinho (PRAÇA 14, 2019). Por estar localizado na área central de Manaus, o bairro Praça 14 de Janeiro dispõe de boa estrutura urbana. O bairro é também conhecido por concentrar um grande número de lojas de produtos automotivos, como autopeças, borracharias e oficinas.

Assim, não há como falar do bairro Praça 14 de Janeiro sem falar da Escola de Samba Vitória Régia e das manifestações religiosas, sejam elas afro-brasileiras, que ocorriam desde seu início, quando a área ainda era conhecida por Vila Maranhense, ou católicas, trazidas pelos imigrantes portugueses. Hoje, além dos descendentes de maranhenses e portugueses, o bairro possui uma população bastante diversificada e miscigenada.

\section{DESCRIÇÃO E ANÁLISE DOS RESULTADOS}

Antes de apresentarmos os resultados, é necessário destacarmos as variáveis controladas nesta pesquisa. Nossa variável dependente é binária, composta pela manutenção do ditongo [ow] e pela redução do ditongo a um único segmento vocálico [o]. As variáveis independentes, também chamadas de condicionadores ou grupos de fatores, inicialmente controladas foram:

Variáveis independentes extralinguísticas (sociais):

"Sexo": homem e mulher;

"Faixa etária”: 18 a 35 anos, 36 a 55 anos e 56 anos em diante;

Variáveis independentes linguísticas:

"Posição do ditongo na palavra": inicial, medial e final;

“Tonicidade”: tônico e átono;

"Classe gramatical”: verbo, substantivo e outros;

"Contexto seguinte”: oclusivas bilabiais [p, b], oclusivas alveolares [t, d], oclusivas velares [k, g], tepe, outras consoantes, pausa e vogais;

Embora a escolaridade não seja um grupo de fatores a ser controlado na pesquisa, uma vez que todos os informantes possuem de 4 a 8 anos de escolaridade, ela não será desconsiderada em nossa análise.

Na Tabela 2, apresentamos os seis informantes - identificados por siglas formadas por letras, em que "H” significa "homem" e "M" "mulher", e números, que correspondem às três faixas etárias controladas, sendo “ 1 ” de 18 a 35 anos, “2” de 36 a 55 e "3” 56 em diante - e o número de ocorrências das variantes de nosso fenômeno variável de acordo com a estratificação social. 
Tabela 2: Número de dados de acordo com a estratificação social dos informantes

\begin{tabular}{|c|c|c|c|c|c|c|}
\hline \multicolumn{2}{|c|}{ Entrevistas } & \multicolumn{2}{|c|}{ Grupos de Fatores Sociais } & \multicolumn{2}{|c|}{ Número de dados } & \multirow[t]{2}{*}{ Total } \\
\hline $\mathbf{N}^{\mathbf{0}}$ & Informante & Sexo & Faixa etária & [o] & [ow] & \\
\hline 1 & $\mathrm{H} 1$ & Homem & 18 а 35 & 15 & 3 & 18 \\
\hline 2 & M1 & Mulher & 18 a 35 & 46 & 4 & 50 \\
\hline 3 & $\mathrm{H} 2$ & Homem & 36 a 55 & 20 & 14 & 34 \\
\hline 4 & M2 & Mulher & 36 a 55 & 28 & 25 & 53 \\
\hline 5 & H3 & Homem & 56 em diante & 45 & 46 & 91 \\
\hline 6 & M3 & Mulher & 56 em diante & 53 & 19 & 72 \\
\hline \multicolumn{4}{|c|}{ Total Geral } & 207 & 111 & 318 \\
\hline
\end{tabular}

Fonte: Elaboração própria

É perceptível que a forma monotongada [o] ocorreu com mais frequência do que a manutenção do ditongo [ow] na maioria dos informantes, exceto no informante 5, homem com mais de 56 anos, que, apesar de ter mantido mais o ditongo em sua fala, a frequência de uso das duas variantes se mostrou bem próxima, assim como na informante 4.

Conforme já mencionado, estudos como o de Veado (1983), Lopes (2002) e Cristofolini (2011) apontam a redução do ditongo /ow/ como praticamente efetivada no PB, pois a forma monotongada atingiu mais de $90 \%$ das ocorrências nessas pesquisas. Apenas o estudo de Cruz (2004) para o Atlas Linguístico do Amazonas (ALAM) indica que tal ditongo é ainda bastante produtivo nos falares amazonenses, ocorrendo em 49,3\% dos dados, em variação com a monotongação, que chega a 50,6\%. Com base nesses estudos, e por se tratar de um fenômeno que, supostamente, não apresenta avaliação social negativa, nossa hipótese era a de que os moradores da Praça 14 de Janeiro utilizariam mais a forma reduzida do ditongo em vez de sua manutenção.

Apresentamos o resultado geral com o número de ocorrências e frequência de uso da realização variável do ditongo /ow/ em nossa amostra de fala:

Tabela 3: Frequência geral da realização variável do ditongo /ow/

\begin{tabular}{c|c|c}
\hline Variantes & Ocorrências & $\mathbf{\%}$ \\
\hline$[\mathrm{o}]-$ Redução do ditongo & 207 & 65,1 \\
\hline$[\mathrm{ow}]-$ Manutenção do ditongo & 111 & 34,9 \\
\hline Total & $\mathbf{3 1 8}$ & \\
\hline
\end{tabular}

Fonte: Elaboração própria

Apesar de, em grande parte dos estudos citados sobre o mesmo fenômeno em outras localidades do Brasil, o número de ocorrências de monotongação ter sido superior a 90\%, em nossa pesquisa os números se mostraram bem menores - ainda que a forma monotongada seja a mais produzida pelos falantes de nossa amostra, conforme nossa hipótese -, chegando a somente 65,1\% das ocorrências. Assim, podemos afirmar que nossos resultados corroboram os de Cruz (2004), pois, em nossa amostra, a manutenção do ditongo /ow/ ainda é produtiva na fala, estando em variação com a sua redução. 
A seguir, apresentamos os resultados para cada variável independente selecionada pelo GoldVarb X, conforme a ordem de relevância para a aplicação da regra de redução de /ow/, sendo elas: "faixa etária”, “contexto seguinte”, "sexo” e “tonicidade”. As variáveis "posição do ditongo na palavra” e "classe gramatical” não foram selecionadas, porém apresentaremos os resultados em percentuais. As particularidades das rodadas estatísticas como amálgamas e exclusão de fatores serão descritas nas seções de suas respectivas variáveis.

\section{VARIÁVEL “FAIXA ETÁRIA”}

Como apresentado nos estudos sobre o fenômeno no PB, grupos de fatores de ordem social não se mostraram significativos para aplicação da regra de monotongação, o que auxiliou na formulação de nossa hipótese de que a “faixa etária” não seria relevante para a “escolha” entre uma ou outra variante. No entanto, essa foi a primeira variável selecionada pelo programa nesta pesquisa. No estudo de Carvalho (2007) sobre os ditongos decrescentes orais na fala de Recife, a "faixa etária” também foi relevante para aplicação da regra de apagamento do glide /w/, em que o fator favorecedor foi a segunda faixa etária (26 a 49 anos) com 81\% de frequência e 0,63 de peso relativo, seguido da primeira faixa (17 a 25 anos) com 83\% e 0,45, e da terceira (mais de 50 anos) com $66 \%$ e 0,38 . Eis, na Tabela 4, os resultados obtidos:

Tabela 4: Frequência e probabilidade da variante [o], segundo a variável faixa etária

\begin{tabular}{|c|c|c|c|}
\hline $\begin{array}{r}\text { Fatores } \\
\end{array}$ & Aplicação/ Total & $\%$ & P.R \\
\hline $1^{\text {a }}$ faixa etária (18 a 35 anos) & $61 / 68$ & 89,7 & 0,79 \\
\hline $3^{\text {a }}$ faixa etária (56 em diante) & $98 / 163$ & 60,1 & 0,45 \\
\hline $2^{\text {a }}$ faixa etária (36 a 55 anos) & $48 / 87$ & 55,2 & 0,33 \\
\hline $\begin{array}{l}\text { Significância: } 0,010 \\
\text { Input: } 0,681\end{array}$ & & & \\
\hline
\end{tabular}

Fonte: Elaboração própria

Os resultados ilustrados na Tabela 4 são contrários à hipótese levantada inicialmente, pois a regra de monotongação se mostrou favorável na $1^{\text {a }}$ faixa etária, com 89,7\% de frequência e peso relativo de 0,79. Em nossa amostra, falantes mais jovens tendem a monotongar mais do que as demais faixas, que se mostraram desfavorecedoras em relação à aplicação da regra, dado que a $3^{\mathrm{a}}$ faixa etária obteve $60,1 \%$ de frequência e peso relativo 0,45 , seguida da $2^{\mathrm{a}}$ faixa etária com $55,2 \%$ e peso relativo de 0,33 . Vale destacar que, em todas as faixas, a forma monotongada ultrapassou a frequência de $50 \%$ das ocorrências.

De acordo com a hipótese “clássica” sobre a mudança linguística na sincronia (WEINREICH; LABOV; HERZOG, 2006 [1968]), o falante preserva o sistema vernacular que foi adquirido até os 15 anos de idade, ou seja, a fala dos mais velhos reflete o vernáculo de seus anos iniciais. Ao analisar os resultados, em que a $1^{\text {a }}$ faixa se mostrou favorecedora da aplicação da regra, podemos refletir sobre um possível indicativo de mudança em curso em que a variante [o], a forma inovadora mais frequente entre os jovens, está substituindo gradativamente a variante [ow], forma ainda produtiva entre os mais velhos. No entanto, devido à extensão deste estudo e às limitações de nossa amostra, não podemos afirmar isso de forma categórica. 


\section{VARIÁVEL “CONTEXTO SEGUINTE”}

A segunda variável selecionada foi “contexto seguinte”. No trabalho de Veado (1983), não foram encontrados contextos bloqueadores para a redução de /ow/, ou seja, condicionamentos de caráter fonético não foram operantes para o apagamento de /w/. Para Cristofolini (2011), essa variável não foi selecionada pelo programa estatístico, porém os contextos que apresentaram maior frequência de monotongação foram o tepe, com 100\%, as oclusivas com 96\% e diante de pausa com 93\% de redução. Nossa hipótese era a de que a variante [o] se daria com maior frequência diante de pausa em virtude do uso frequente de formas verbais na $3^{\mathrm{a}}$ pessoa do singular, como em “chegou”. Os resultados encontrados foram:

Tabela 5: Frequência e probabilidade da variante [o], segundo a variável contexto seguinte

\begin{tabular}{l|c|c|c}
\hline \multicolumn{1}{c|}{ Fatores } & Aplicação/ Total & $\mathbf{\%}$ & P.R \\
\hline Pausa & $132 / 197$ & 67,0 & 0,52 \\
\hline Consoantes oclusivas & $63 / 95$ & 66,3 & 0,51 \\
\hline Outras consoantes & $6 / 20$ & 30,0 & 0,21 \\
\hline
\end{tabular}

Significância: 0,010

Input: 0,681

\section{Fonte: Elaboração própria}

Mesmo que os pesos relativos estejam próximos do ponto neutro $(0,50)$ - o que indica que tais fatores pesam pouco para a aplicação da regra -, nossa hipótese se sustentou, uma vez que o contexto mais favorecedor para a redução do ditongo foi diante de pausa, como em "piorô", com $67,0 \%$ de frequência e peso relativo 0,52 . O segundo fator favorecedor foi "consoantes oclusivas" com 66,3\% de frequência e 0,51 de peso relativo, provavelmente em virtude do grande número de ocorrências da palavra “outro” e suas flexões como “outros”, “outra” e “outras”.

Devemos destacar que, inicialmente, os fatores desse grupo eram outros, porém para eliminar knockouts e/ou enviesamentos, alguns fatores tiveram que ser amalgamados e outros excluídos da análise. Os fatores “oclusivas bilabiais [p, b]”, “oclusivas alveolares [t, d]” e "oclusivas velares [k, g]” foram agrupados de acordo com o modo de articulação e recodificados como "consoantes oclusivas”, já que alguns apresentaram poucas ocorrências, causando resultados enviesados. O fator "tepe" foi amalgamado com o fator "outras consoantes", também em virtude do baixo número de ocorrências. O fator "vogal” ocorreu em apenas 6 dados, em expressões como "tentô ir" e "mandô ela” com 100\% de redução, gerando knockout. Em razão de suas características articulatórias, não foi possível fazer amálgama com outros fatores, restando excluir esse fator da rodada estatística.

\section{VARIÁVEL “SEXO”}

Em estudos variacionistas, como o de Veado (1983) e, mais recentemente, de Cristofolini (2011), o grupo de fatores “sexo” não se mostrou relevante para a redução do ditongo /ow/. Nossa hipótese era a de que fatores sociais como "sexo" não influenciariam de forma significativa 
a monotongação. No entanto, esta foi a terceira variável selecionada pelo programa após as rodadas estatísticas. Os resultados foram os seguintes:

Tabela 6: Frequência e probabilidade da variante [o], segundo a variável sexo

\begin{tabular}{l|c|c|c}
\hline \multicolumn{1}{c|}{ Fatores } & Aplicação/ Total & $\mathbf{\%}$ & P.R \\
\hline Mulher & $127 / 175$ & 72,6 & 0,58 \\
\hline Homem & $80 / 143$ & 55,9 & 0,40 \\
\hline
\end{tabular}

Significância: 0,010

Input: 0,681

Fonte: Elaboração própria

Podemos notar que as mulheres utilizaram mais a forma reduzida do ditongo, com 72,6\% de frequência de uso e com peso relativo 0,58 , enquanto os homens utilizaram a variante reduzida em $55,9 \%$ dos dados e com peso relativo de 0,40 . Ou seja, as mulheres se mostraram mais favoráveis à aplicação da regra, porém, se compararmos em termos de peso relativo, a diferença entre os fatores não foi expressiva, o que não anula por completo nossa hipótese, uma vez que os resultados estão próximos da neutralidade, ou seja, tem pouco peso na aplicação da regra. Segundo Labov (2008 [1972]), as mulheres ocidentais tendem a usar as formas mais prestigiadas, porém, como as variantes de nossa variável dependente não possuem avaliação negativa, as mulheres se mostraram mais favoráveis ao uso da forma reduzida.

Ao correlacionar as variáveis "sexo" e "faixa etária”, os dados apontaram que o percentual de produção da variante [o] por mulheres se deu em maior número na $1^{a}$ faixa etária - selecionada como o fator mais favorecedor para a redução de /ow/ - em que, do total de 50 dados, 92\% foram da forma reduzida [o]. O percentual de ocorrência da utilização de [o] por mulheres nas demais faixas segue a mesma ordem de seleção da variável "faixa etária”, em que a $3^{\mathrm{a}}$ faixa aparece na posição intermediária, com $74 \%$, e a $2^{\mathrm{a}}$ faixa na última posição, com $53 \%$ de dados monotongados. Comparando a "faixa etária" ao percentual de dados monotongados produzido por homens, apenas na $2^{\mathrm{a}}$ faixa eles apresentaram um índice maior de utilização da forma reduzida [o] em comparação com as mulheres da mesma faixa, que, de 34 dados, 20 foram com a variante [o], o que corresponde a 59\% das ocorrências.

Tabela 7: Correlação entre as variáveis sexo e faixa etária para a variante [o]

\begin{tabular}{c|c|c|c|c}
\cline { 2 - 5 } \multicolumn{2}{c}{} & \multicolumn{4}{c}{ Sexo } \\
\hline Faixa etária & Aplic./ Total & $\%$ & Aplic./ Total & $\%$ \\
\hline $1-18$ a 35 anos & $15 / 18$ & $83,0 \%$ & $46 / 50$ & $92,0 \%$ \\
\hline $2-36$ a 55 anos & $20 / 34$ & $59,0 \%$ & $28 / 53$ & $53,0 \%$ \\
\hline $3-56$ em diante & $45 / 91$ & $49,0 \%$ & $53 / 72$ & $74,0 \%$ \\
\hline
\end{tabular}

Fonte: Elaboração própria

Os resultados da variável "sexo" corroboram os da "faixa etária”, de que uma possível mudança esteja em andamento, pois, além dos mais jovens, as mulheres utilizaram mais a 
variante inovadora, a forma monotongada, já que geralmente as mulheres são responsáveis pela mudança quando a variante não possui avaliação negativa. Porém, como já citado, os resultados se aplicam à nossa amostra, não podendo ser generalizados para o falar manauara.

\section{VARIÁVEL “TONICIDADE”}

Esta foi a última variável selecionada, porém foi a variável linguística que apresentou números maiores de peso relativo para a aplicação da regra. Para Carvalho (2007) e Cristofolini (2011), a “tonicidade” se mostrou a variável linguística mais relevante para a redução de /ow/, sendo a sílaba tônica o fator favorecedor para a monotongação. Com base nesses estudos, nossa hipótese era a de que as sílabas tônicas favoreceriam a monotongação de /ow/. No entanto, nossa hipótese foi refutada e nossos resultados foram outros:

Tabela 8: Frequência e probabilidade da variante [o], segundo a variável tonicidade

\begin{tabular}{l|c|c|c}
\hline \multicolumn{1}{c|}{ Fatores } & Aplicação/ Total & $\mathbf{\%}$ & P.R \\
\hline Átono & $18 / 23$ & 78,3 & 0,79 \\
\hline Tônico & $189 / 295$ & 64,1 & 0,47 \\
\hline
\end{tabular}

Significância: 0,010

Input: 0,681

Fonte: Elaboração própria

Em nossa análise, o programa estatístico selecionou o fator "átono" como favorecedor para a aplicação da regra com 78,3\% de frequência e peso relativo de 0,79 , e ocorreu, quase sempre, em palavras derivadas como "p[o]quinho" e "r[o]bado". Apesar da forma reduzida em sílabas tônicas ser maior em termos de número de ocorrências devido à grande quantidade de formas verbais na terceira pessoa e da palavra "outro" e suas flexões, tal fator apresentou somente $64,1 \%$ de frequência e peso relativo de 0,47 . Esses resultados confirmam a teoria de que, em geral, as sílabas átonas são mais sujeitas aos processos fonológicos que envolvem redução segmental por serem menos salientes e terem duração menor do que as sílabas tônicas, que são mais resistentes a tais processos (SILVA, 2015).

\section{VARIÁVEIS NÃO SELECIONADAS}

Nesta seção, apresentamos as variáveis independentes não selecionadas pelo programa estatístico como relevantes para a aplicação da regra, mas que merecem algumas considerações.

A primeira variável descartada foi a "posição do ditongo na palavra”, cujos fatores controlados foram a posição na sílaba "inicial”, "medial” e "final”. Na primeira rodada estatística, o fator "posição medial" apresentou knockout com 100\% de frequência da variante [ow], correspondendo a 10 dados do corpus. As ocorrências foram em palavras fonológicas como "achou que”, e em formas como "formou-se", “casou-se” e "acabou-se”, sendo 9 dados produzidos pelo informante H3 (homem, mais de 56 anos). Não foram registradas ocorrências do ditongo /ow/ em posição medial em formas não verbais. Como o fator "posição medial” apresentou knockout, 
fizemos amálgama com o fator "posição inicial”, que apresentou poucos dados, ficando ao fim da análise apenas dois fatores nesse grupo: "outras posições” e "posição final”.

No trabalho de Veado (1983), a posição em que mais ocorreu a redução do ditongo foi em final de palavra, embora, segundo a autora, não se pode afirmar que as outras posições são desfavorecedoras, sendo apenas uma questão de grau de favorecimento. Os resultados de Lopes (2002) confirmam os de Veado (1983), uma vez que a posição final de vocábulo foi o ambiente mais propício para o apagamento de /w/. Desse modo, nossa hipótese era a de que ditongos situados em posição final apresentariam maior grau de redução, o que de fato ocorreu, conforme Gráfico 1:

Gráfico 1: Frequência das variantes [o] e [ow], conforme a variável posição do ditongo na palavra

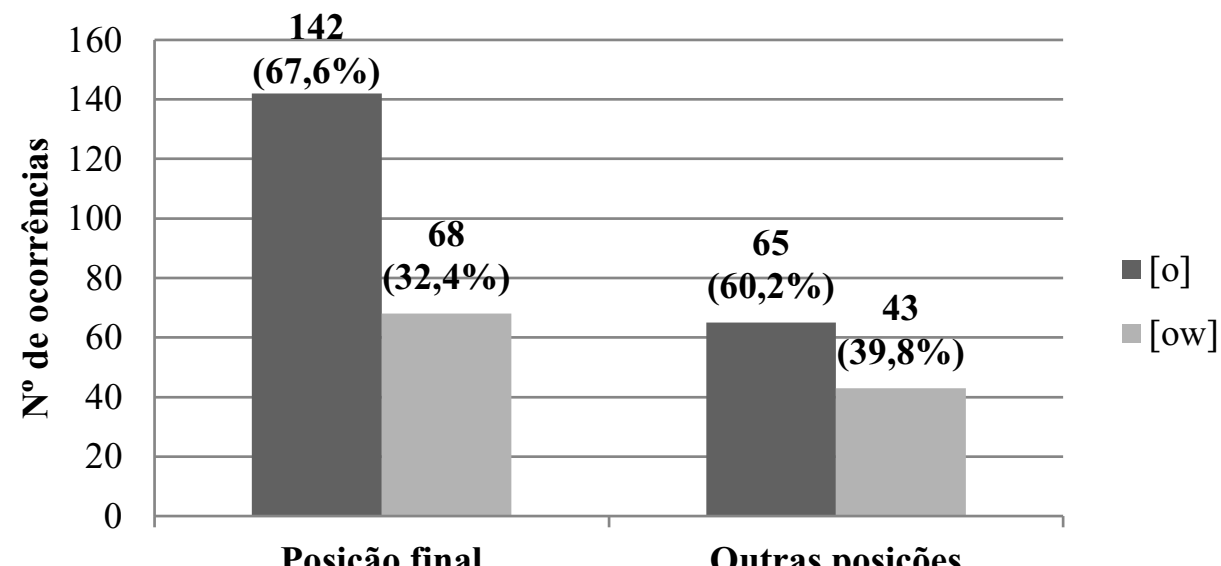

Fonte: Elaboração própria

De acordo com o Gráfico 1, ditongos situados em posição final de palavra apresentaram maior redução, uma vez que, dos 210 dados nessa posição, em 142 houve a redução do ditongo. Já nas demais posições, de 108 dados, em 65 houve redução. Porém, comparando os fatores, notamos que os resultados não apresentam grandes diferenças em termos de frequência de uso. Em posição final, a redução do ditongo para [o] ocorreu em $67,6 \%$ dos dados, enquanto nas demais posições, a redução ocorreu em 60,2\% dos dados. Dessa forma, de acordo com Veado (1983), a posição com maior frequência foi a posição final, porém isso não quer dizer a redução do ditongo não ocorra com alto índice de frequência nas demais posições.

A segunda variável não selecionada pelo programa estatístico foi "classe gramatical”, cujos fatores controlados inicialmente foram "verbo", "substantivo" e "outros". Como o número de dados para o fator "substantivo" foi bastante reduzido, apenas 13 ocorrências em comparação ao número excessivo de "verbos", optamos por amalgamar os fatores "substantivo" e "outros", ficando ao final da análise os fatores "verbos" e "não verbos".

Lopes (2002) e Cristofolini (2011) também trabalharam com essa variável independente, porém, como em nossa análise, o programa estatístico não a selecionou como relevante para a aplicação da regra de monotongação de /ow/. Nossa hipótese, ainda que de forma intuitiva, era a de que a redução do ditongo se daria com maior frequência em verbos, devido ao uso constante 
de formas verbais conjugadas na $3^{\mathrm{a}}$ pessoa do singular do Pretérito Perfeito do Indicativo, comuns em narrativas de relato de experiências pessoais presentes na entrevista sociolinguística. Vamos aos resultados:

Gráfico 2: Frequência das variantes [o] e [ow], conforme a variável classe gramatical

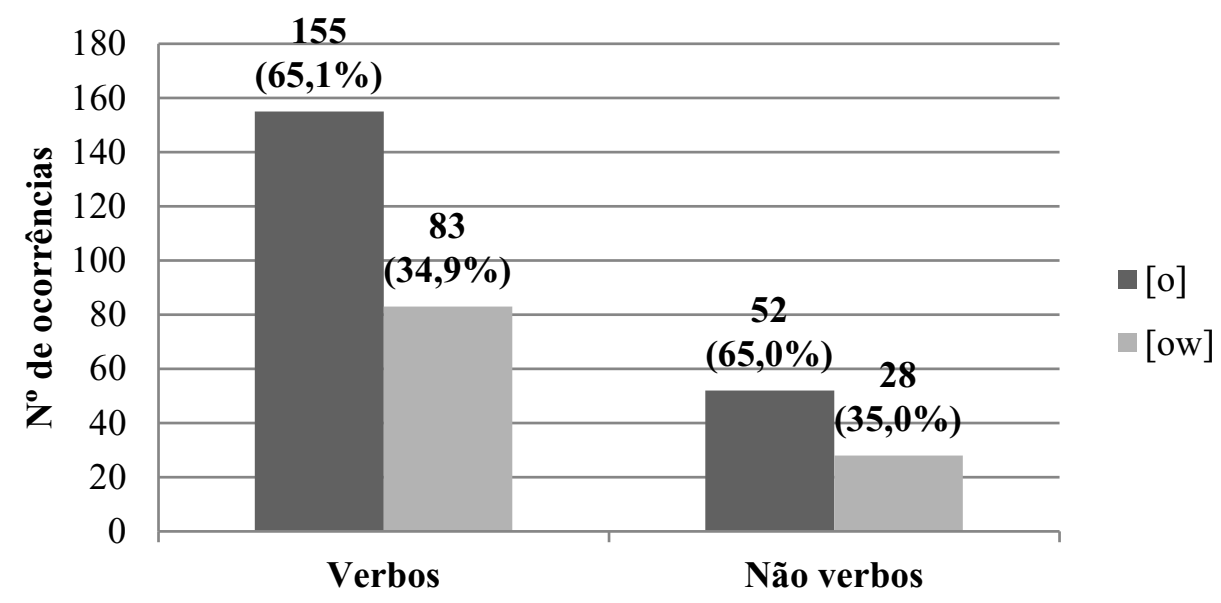

Fonte: Elaboração própria

Comparando o número de ocorrências de cada fator, obtivemos o total de 238 dados de ditongos presentes em verbos, dos quais, em 155, o que corresponde a 65,1\% das ocorrências, houve a redução para [o]; já dos 80 dados presentes em outras classes de palavras, a forma monotongada ocorreu em 52 dados, o que corresponde a 65\% das ocorrências. Embora o fator "verbos" tenha apresentado um número bem maior de ocorrências, em termos percentuais a frequência de uso está praticamente equiparada com a frequência de redução do ditongo em "não verbos”. Como a amostra é constituída por um número maior de verbos, não é possível verificar a validade de nossa hipótese, já que a frequência de uso não pode ser usada como parâmetro.

\section{ALGUNS APONTAMENTOS}

neste estudo piloto, procuramos estudar um fenômeno tão presente e comum em nossa língua, que, muitas vezes, nem mesmo nos damos conta de que ele existe. Estamos falando da monotongação, ou seja, do processo pelo qual um ditongo pode ser reduzido a um único segmento vocálico, como quando falamos “caxa” e “otro” em vez de "caixa” e “outro”. Nosso foco foi a realização variável do ditongo /ow/, mantido como [ow] ou reduzido para [o], sob a perspectiva da sociolinguística variacionista.

Nas pesquisas destacadas neste artigo sobre o mesmo fenômeno em diferentes localidades do Brasil, a redução de tal ditongo oral decrescente é um processo quase efetivado na fala, uma vez que ocorreu em mais de $90 \%$ dos dados analisados nos estudos pelo país. Em nossa amostra, no entanto, podemos dizer que a realização do ditongo /ow/ ainda é um processo variável, uma vez que a redução ocorreu em torno de $60 \%$ dos dados analisados. 
Sobre as variáveis relevantes para a aplicação da regra de redução do ditongo /ow/, o programa selecionou: "faixa etária", “contexto seguinte”, "sexo" e "tonicidade”. Dos grupos de fatores sociais, o que apresentou maior peso relativo para a aplicação da regra de monotongação foi a "faixa etária", sendo a $1^{\text {a }}$ faixa a mais favorecedora $(0,79)$, seguida da $3^{\mathrm{a}}$ faixa $(0,45)$ e da $2^{a}$ faixa $(0,33)$. Em relação ao "sexo", as mulheres de nossa amostra se mostraram mais favoráveis a usar a forma monotongada $(0,58)$ do que os homens $(0,40)$. Dos grupos de fatores linguísticos, embora o "contexto seguinte" tenha se mostrado significativo, os resultados dos fatores "pausa" e "consoantes oclusivas" foram semelhantes, com pesos relativos de 0,52 e 0,51 , respectivamente. Notemos que tais resultados estão próximos do ponto neutro, o que indica que o contexto seguinte não tem grande força para a redução do ditongo /ow/. O fator "outras consoantes", que, além de "tepe”, reúne consoantes com poucas ocorrências, apresentou apenas 0,21. No entanto, a "tonicidade” mostrou ter papel importante para a monotongação, pois, nas sílabas átonas, aquelas mais sujeitas a processos fonológicos de redução segmental, há maior probabilidade de redução de [ow] para [o], com peso relativo de 0,79 , contra 0,47 das sílabas tônicas.

Podemos afirmar que, em nossa amostra, a manutenção do ditongo /ow/ ainda é produtiva, o que diverge de alguns resultados de outros estudos brevemente apresentados neste trabalho. Vale ressaltar que não podemos fazer generalizações quanto aos resultados deste estudo, muito menos estendê-los ao falar amazonense - sequer ao falar manauara - uma vez que nossa amostra conta com apenas um informante por célula social, totalizando seis informantes, o que não deixa de ser uma limitação para este estudo. Portanto, os resultados aqui apresentados refletem os usos linguísticos de nossa amostra, os seis informantes do bairro Praça 14 de Janeiro, em Manaus (AM).

Devemos ressaltar que os informantes de nossa amostra possuem de 4 a 8 anos de escolaridade e, mesmo assim, utilizaram bem menos a forma monotongada do que falantes de várias escolaridades do restante do país, conforme descrito nas pesquisas consultadas. No entanto, não podemos afirmar se a escolaridade é relevante para a realização variável do ditongo /ow/, pois ela não foi controlada em nossa pesquisa. Um estudo mais amplo na comunidade de fala manauara seria pertinente para comparação dos resultados aqui obtidos com os de outros estudos do Brasil. Contudo, acreditamos que esta pesquisa variacionista possibilitará um maior entendimento sobre o funcionamento de nossa variedade linguística e contribuirá com a produção do conhecimento científico no Amazonas.

\section{REFERÊNCIAS}

BISOL, L. (Org.). Introdução a Estudos de Fonologia do Português Brasileiro. 2. ed. Porto Alegre: EDIPUCRS, 1999.

CAGLIARI, L. C. Elementos de Fonética do Português Brasileiro. São Paulo: Paulistana, 2007.

CARVALHO, S. C. de. Estudo variável do apagamento dos ditongos decrescentes orais na fala de Recife. 2007. 102 f. Dissertação (Mestrado em Linguística) - Universidade Federal de Pernambuco, Recife, 2007.

COELHO, I. L.et. al. Para conhecer sociolinguística. São Paulo: Contexto, 2018. 
CRISTOFOLINI, C. Estudo da monotongação de [ow] no falar florianopolitano: perspectiva acústica e sociolinguística. Revista da ABRALIN, v.10, n.1, p. 205-229, jan./jun. 2011

CRUZ, M. L. de C. Atlas linguístico do Amazonas. 2004. Tese (Doutorado em Letras Vernáculas) - Universidade Federal do Rio de Janeiro, Rio de Janeiro, 2004. 2 v. Vol I: 159 p. mimeo. Vol II: tomo 1: 110 p. mimeo; tomo 2: 260 mapas.

GUY, G.; ZILLES, A. Sociolinguística quantitativa - instrumental de análise. São Paulo: Parábola Editorial, 2007.

IBGE. Divisão regional do Brasil em regiões geográficas imediatas e regiões geográficas intermediárias. Coordenação de Geografia. Rio de Janeiro: IBGE, 2017. Disponível em: https://biblioteca.ibge.gov.br/visualizacao/livros/liv100600.pdf. Acesso em: 13 maio 2020.

LABOV, W. Padrões sociolinguísticos. Tradução: Marcos Bagno, Maria Marta Pereira Scherre, Carolina Rodrigues Cardoso. São Paulo: Parábola Editorial, 2008 [1972].

LOPES, R.A realização variável dos ditongos /ow/e /ej/ no português falado em Altamira/PA. 2002. 97 f. Dissertação (Mestrado em Linguística) - Universidade Federal do Pará, Belém, 2002.

NUNES, P. A. Conheça a história do bairro Praça 14 de Janeiro, berço do samba de Manaus. A Crítica, Manaus, 12 jan. 2018. Disponível em: https://www.acritica.com/channels/especiais/ news/saiba-mais-sobre-a-historia-da-praca-14-de-janeiro-onde-nasceu-o-samba-de-manaus. Acesso em: 10 maio 2020.

PEDROSA, F. A. de C. Praça 14 de Janeiro. Jornal do Commercio, Manaus. 16 jan. 2020. Disponível em: https://www.jcam.com.br/Noticia/Praca-14-de-Janeiro-51936\#.XrriPERKjIU. Acesso em: 12 maio 2020.

PRAÇA 14: um bairro de samba, quilombolas e Nossa Senhora de Fátima. Em tempo, Manaus, 14 jan. 2019. História dos bairros. Disponível em: https://d.emtempo.com.br/ amazonas/134648/praca-14-um-bairro-de-samba-quilombolas-e-nossa-senhora-de-fatima. Acesso em: 13 maio 2020.

PRAÇA 14 - Fruto da Revolução de 1892. Jornal do Commercio, Manaus, Edição n. 39.436, p. 103, 23 e 24 out. 2005.

SANKOFF, D.; TAGLIAMONTE, S. A.; SMITH, E. GoldVarb X: A variable rule application for Macintosh and Windows. Department of Linguistics, University of Toronto, 2005.

SEARA, I. C.; NUNES, V. G.; LAZZAROTTO-VOLCÃO, C. Para conhecer fonética e fonologia do português brasileiro. 2. ed. $1^{\mathrm{a}}$ reimpressão. São Paulo: Contexto, 2019.

SILVA, M. do P. S. C. da.Interferência da fala na escrita de alunos do ensino médio: descrição e análise de usos de monotongação e de apagamento do [R] final. 2017. 163 f. Dissertação (Mestrado em Letras) - Universidade Federal do Amazonas, Manaus, 2017.

SILVA, T. C. Fonética e fonologia do português: roteiro de estudos e guia de exercícios. 10. ed. São Paulo: Contexto, 2014.

SILVA, T. C. Dicionário de fonética e fonologia. 1. ed. São Paulo: Contexto, 2015. 
VEADO, M. A. Redução de ditongo -uma variável sociolingüística. Ensaios de Lingüística, Belo Horizonte (MG), ano V, n. 9, pp. 209 -229, dez., 1983.

WEINREICH, U.; LABOV, W.; HERZOG, M. I. Fundamentos empíricos para uma teoria da mudança linguística. Tradução: Marcos Bagno. São Paulo: Parábola, 2006 [1968].

Recebido em: jun. 2020.

Aceito em: set. 2020. 